\title{
SELF-MONITORING AND RECIPROCAL INHIBITION IN THE MODIFICATION OF MULTIPLE TICS OF GILLES DE LA TOURETTE'S SYNDROME*
}

\author{
EDWIN J. THOMAS† \\ School of Social Work and Department of Psychology, University of Michigan \\ Kathleen ShEa ABrams \\ Parkview Rehabilitation Unit, and Department of Psychology, University of Michigan \\ and \\ JAMES B. JOHNSON \\ University of Michigan Medical School

\begin{abstract}
Summary-An 18-year-old male with multiple tics, including a bark-like vocalization and jerking neck movements, as components of the syndrome of Gilles de la Tourette, was treated using an empirically based practice procedure in an investigation that employed a modified multiple-baseline design. In the assessment, instigating and inhibiting stimulus conditions were identified by collecting observational data on the tics in many life situations in and outside of the rehabilitation unit where the therapy was undertaken. Self-monitoring was found to be tic-inhibiting and when it was introduced in the modification for the vocal tic, the rate dropped immediately and dramatically on the first day. Self-monitoring and reciprocal inhibition procedures were subsequently associated with gradual reduction to nearly zero of a newly emerged minor vocal sound and of the neck tic. Evidence also suggested that the haloperidol the patient had taken previous to treatment and took throughout all but 1 week of the treatment period may have helped to reduce the tics.
\end{abstract}

\section{INTRODUCTION}

THE STRANGE syndrome of multiple tics that originates in childhood and consists of compulsive jerking of the voluntary musculature in the face, neck, or extremities combined with coprolalia, echolalia or of other spasmodic involuntary noises is widely known as the maladie de Gilles de la Tourette (Gilles de la Tourette, 1885). Many investigators have observed that these multiple tics are very frequently accompanied by so-called emotional disturbances, such as enuresis, phobias, and aggressiveness (e.g. see Corbett et al., 1969; Lucas, 1967; and Morphew and Sim, 1969). The prognosis was originally thought to be poor and many writers still describe pessimistic prospects. However, recent studies by Corbett et al. (1969) and Lucas (1969), in which this type of tiqueur was followed-up over long periods, now suggest a more favorable prognosis.

The causal basis for the syndrome is unknown. Although particular organic abnormalities have been found in some studies (e.g. see Balthazar, 1957; Erikson, 1965; and Field et al., 1966), other studies involving a relatively large number of subjects have failed to discover any consistent organic problem or history (Corbett et al., 1969; Morphew and Sim, 1969). In addition to functional theories of origin (Ascher, 1948; Mahler, 1944 and 1945; Morphew and Sim, 1969), there

\footnotetext{
*Portions of the first author's work on this project were supported by a grant from the Social and Rehabilitation Service, Department of Health, Education and Welfare, Grant CRD-529-0. Portions of the second author's work on this project were supported by the State of Michigan Division of Vocational Rehabilitation and by Rehabilitation Services Administration, Grant No. 2-75-04.

†Requests for reprints should be addressed to Edwin J. Thomas, The University of Michigan School of Social Work, 1065 Frieze Building, Ann Arbor, Michigan 48104.

$\ddagger$ Present address: Christ Hospital, Cincinnati, Ohio.
} 
are explanations in terms of both functional and organic factors. A clear case for the latter view is presented by Stevens and Blachly (1966) in whose study there was the successful treatment of the malady with a specific drug, haloperidol. This antipsychotic appears to be the most consistently effective drug, although success with it varies from complete, almost immediate relief of symptoms, to no discernible effect (e.g. see Abuzzahab, 1970; Challas and Brauer, 1963; Connell et al., 1967; Ford and Gottlieb, 1969; Healy, 1970; Lucas, 1967; Shapiro and Shapiro, 1968; Stevens and Blachly, 1966).

\section{CASE HISTORY}

The patient is an 18-year-old male whose tics consisted of spasmodic, involuntary jerks of the neck, convulsive-like movements of his hands, and of plosive bursts of air that sounded like a sharp, loud bark. There were many other frequent, minor movements of the extremities, but these were less clearly discernible as discrete, convulsive-like movements. The patient came to our attention 10 days after he was admitted to the Parkview Rehabilitation Unit for an appraisal relating to his vocational potential. His tics were judged by the vocational evaluation staff as sufficiently severe to be a significant vocational and social handicap for mechanical work, his vocational choice. Although his tics did not cause physical interference with his ability to perform manual tasks, the vocal tic was noted to be distracting to co-workers.

Interviews with the parents disclosed that a tic consisting of a muscular movement in the face and mouth was first observed at age 5, 3 months after the patient began school. Before that, the patient was said to be a "high-strung baby" who didn't sleep much, cried and laughed more readily than his brothers, and was "fussy." The noise was first noticed at age 10 or 11 but the parents could not remember when his neck and hand tics developed. They recalled that the patient's tics had been much improved from about age 13 to 14 during which time he and his family lived in a different town where he did not go to school. At that time, the patient had a tutor assigned to him by the school and helped his father take care of the small grocery store and gas station that the father then owned. The year after, the family moved back to the community in which the patient was born. The patient returned to school, and once again the tics became worse. He missed a lot of school during the last 4 years that he attended because of what his parents alleged to be the strain on him to try to keep quiet at school. One teacher had become irritated by his noises and reprimanded him, making him sit in front of the class. That same year, in the eleventh grade, the patient dropped out of school because his tics had increased there and made him very nervous about school.

The family history disclosed that the mother had developed a tic at about the age of 13, following an attack of scarlet fever and the birth of her brother. Her tic was a neck jerk and she occasionally had a vocal tic which was neither as loud nor the same as the patient's. The husband, who had known her at the time, said that he had not noticed any tics. The mother said that her neck movement was worst between the ages of 13 to 16 after which it improved because, she said, she learned to relax and eventually "grew out of it." However, when she gets nervous, she still has a neck and an eyelid twitch, both of which were observed by the interviewer.

The patient's parents claim that they are relatively indulgent with the patient and their other five children although they appear to have strict moral standards. They say that they have not expected as much from the patient as they have of the other children, have tried to keep him calm, have not reprimanded him for his tics and have referred to him as a "handicapped child." He has been unemployed since he left school and has remained at home where he occupies himself with a variety of activities. Although the patient seems to get along well with people and says he likes to meet them, he has not dated and has had relatively few friends.

The patient received a variety of treatments 
for his condition since medical advice was first sought for him at the age of 5 . At various times he has received psychotherapy, milieu therapy and hypnosis in addition to a variety of drugs, such as phenobarbital, meprobamate and haloperidol. The only form of treatment that had produced any benefit was haloperidol. For most of the time since 1968, when he was hospitalized for several months at a child psychiatric facility, the patient had been taking $1 \frac{1}{2} \mathrm{mg}$ two times a day and he said this had a calming effect and reduced the tics somewhat. Larger doses made the patient drowsy and reduced his ability to function normally. Although earlier the patient's condition was given a variety of diagnoses (e.g. Huntington's Chorea), the most recent and authoritative is Gilles de la Tourette. Electroencephalograms had been done on two occasions and were found to be within normal limits. On the Wechsler Intelligence Scale for Children, he performed at age 15 within the average range of intellectual functioning, with a Verbal I.Q. of 106, a Performance I.Q. of 96, and a Full Scale I.Q. of 101 .

\section{ASSESSMENT PROCEDURE AND RESULTS}

In Yates' (1970) appraisal of prior behavioral therapy and research on tics, he observed that most if not all behavioral assessment of tics has been undertaken in laboratory contexts, that the researchers had failed to obtain base rate and assessment data in situations approximating those of real life, and that modification had been mainly experimental rather than therapeutic. In this study, all behavioral assessment and modification were performed in a non-laboratory environment that included the rehabilitation unit and the city in which it is located.

The goal of modification was primarily therapeutic and an empirically-based behavioral practice procedure was followed (Thomas et al., 1970; Gambrill et al., 1971). The steps of the procedure followed here were the specification of the focal behavior, baselining, determination of the controlling conditions associated with the focal behavior, determination of environmental and behavioral resources, specification of behavioral objectives, the formulation of the modification plan, the implementation of the plan, and the monitoring of outcomes.

\section{Specification}

Identification of the component behaviors of the tic syndrome was accomplished by observing the patient for several hours through a one-way mirror while he engaged in different activities. The vocal tic was the most frequent and conspicuous, the neck tic second and the hand movements third. All these had convulsive, involuntary qualities and thus were different from other frequent and repetitive movements of the extremities. At this point, the separate tics appeared to be independent of one another inasmuch as they were not chained together nor were their rates related. It was possible for the patient voluntarily to suppress the tics only to a very minor degree and only for brief periods.

\section{Baselines}

The procedure used to record the tics involved counting and recording every tic in order of occurrence, using a separate row of the record sheet for each $5 \mathrm{sec}$ interval. Major activities of the patient were also recorded for each interval. A cue sound, occurring at 5 sec intervals, which had earlier been recorded on a cassette tape, was listened to during observation with an inconspicuous ear attachment that made it possible for the observer alone to hear the cue sound. Reliability training was accomplished by having two or more observers code the patient's tics while observing him through a one-way mirror and being cued by interval sounds which, in this instance, were made audible to all observers. The practice sessions served to increase the reliability of coding. We learned from these sessions that only one tic at a time could be counted reliably in $5 \mathrm{sec}$ intervals and that activity recording could include only major activities.

Reliability checks were based upon four $5 \mathrm{~min}$ samples of observation, using two observers, 
with the patient engaged in various, voluntary activities in real-life situations. Of a total of 106 judgments, 80 per cent fell within the same $5 \mathrm{sec}$ intervals and 98 per cent within the same or adjacent intervals. Ninety-eight per cent agreement was achieved on the number of judgments in the total time period. Two 5 min periods were used to check on the coding reliability for the neck tics. Here the percentages of agreement were 34 for coding in the same $5 \mathrm{sec}$ intervals, 69 for coding in the same or adjacent $5 \mathrm{sec}$ intervals, and 90 for agreement on the total number counted. Clearly, the vocal tics could be coded more reliably than the neck tics.

Because it was impossible for an observer to record reliably more than one tic at a time, a modified multiple baseline design was used. First, the vocal tic was baselined and modified, then a newly developed minor vocal sound and the neck tic were baselined and each modified, beginning with the minor vocal sound.

Observations were taken of the tics in two types of real-life situations. The first consisted of those to which the patient voluntarily exposed himself and that occurred mainly in the institution. This was referred to as Tagalong observation because the observer, following a period of adaptation to his presence by the patient and others in the rehabilitation unit, followed the patient as unobtrusively as possible everywhere he went. For the most part, the patient was observed in Tagalong situations for $15 \mathrm{~min}$, followed by $15 \mathrm{~min}$ rest for the observer. Table 1 shows the types of situations in which the patient was observed for the first day of baseline observation. The table also indicates that there were eight $15 \mathrm{~min}$ observational periods beginning in the late afternoon and continuing into the early evening. For the time involved, a total daily rate of 449 vocal tics was recorded, yielding 3.7 as the daily rate of tics per min. It is this daily rate for the first day of baselining that is plotted on Fig. 1. The analogous rate for Tagalong observation periods two days later was $4 \cdot 5$. Figure 1 also indicates that the neck tic occurred at a lower rate than the vocal tic and was more variable; and that prior to modification the minor vocal sounds never attained a very high rate and were somewhat variable.

The second type of observation was undertaken in connection with planned exposure by the therapist of the patient to different real-life situations, most of which were common to life outside an institution (Fig. $2 \mathrm{a}-\mathrm{g}$ ). The cleaners and drug store, church, high school, restaurant, public library and supermarket were selected

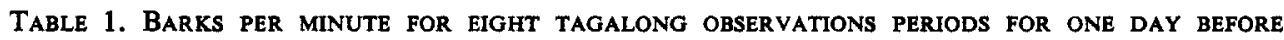
INTERVENTION (2 NOVEMBER)

\begin{tabular}{|c|c|c|c|}
\hline Time & Tics & Tics per minute & Activity \\
\hline $4: 22-4: 37$ & 30 & $2 \cdot 0$ & Reading aloud in own hospital room. \\
\hline $4: 52-5: 07$ & 52 & $3 \cdot 5$ & Playing guitar and singing intermittently. \\
\hline $5: 23-5: 38$ & 102 & $6 \cdot 8$ & $\begin{array}{l}\text { Finishing meal in dining room, laughing, } \\
\text { joking and talking with five other patients. }\end{array}$ \\
\hline $5: 55-6: 10$ & 37 & $2 \cdot 5$ & $\begin{array}{l}\text { Typing in O.T. room; girl later sits next to } \\
\text { patient. }\end{array}$ \\
\hline $6: 25-6: 40$ & 79 & $5 \cdot 3$ & $\begin{array}{l}\text { Talking, laughing, joking in female friend's } \\
\text { room. }\end{array}$ \\
\hline $6: 56-7: 11$ & 57 & $3 \cdot 8$ & Talking with female in her room. \\
\hline $7: 28-7: 43$ & 52 & $3 \cdot 5$ & $\begin{array}{l}\text { Talking with female, combing her hair, in } \\
\text { her room. }\end{array}$ \\
\hline $7: 58-8: 13$ & 40 & $2 \cdot 7$ & $\begin{array}{l}\text { Entering own room, greets new roommate, } \\
\text { reads magazine on mechanics. }\end{array}$ \\
\hline $\begin{array}{l}\text { All periods for } \\
2 \text { November }\end{array}$ & 449 & $3 \cdot 7$ & \\
\hline
\end{tabular}




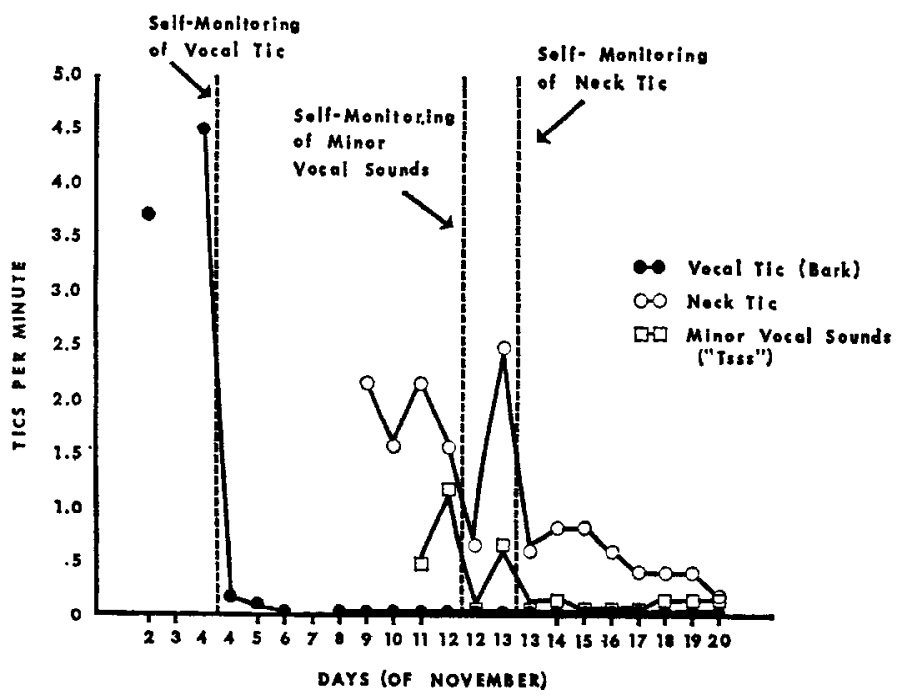

FIG. 1. Tics per min for daily Tagalong observation periods before and after modification by self-monitoring of vocal tic, minor vocal sounds, and neck tic. The number of daily observation sessions had a range from 1 to 13 , the average being about 3-4 per day. Almost all observation sessions lasted $15 \mathrm{~min}$. The number of min of observation per day had a range from 15 to 186 , with an average of approximately 51 .

because the rate of tic behavior in these situations was either judged by the observer to be higher or was thought by the patient to be elevated. The patient's hospital room and the observation room were included because the patient thought that his tics occurred less frequently in these places. The itinerary for these so-called Exposure Tours was selected by the therapists and required the patient to enter the situation in question for about $10 \mathrm{~min}$. In most cases, they were situations that the patient would not necessarily enter in the normal course of events while in the rehabilitation unit.

Figures $2 a, b$ and $c$ indicate that for the vocal tic, the cleaners and the drug store yielded the highest rate $(5 \cdot 8)$, that the church yielded a relatively high rate $(4 \cdot 1)$, and that the patient's hospital room yielded a relatively low rate $(1 \cdot 8)$. In these situations, comparable rates were found for the neck tic and, altogether, the rates for the neck tic ranged from $2 \cdot 2$, for the restaurant, to 5.8 for the cleaners and drug store. However, it should be noted that the neck tic diminished in all those situations in which observations. were taken on at least two occasions prior to its planned modification. The rates for the minor vocal sound were less than 1 per min and were about the same in the three situations in which they were sampled prior to modification (see Figs. 2a, $d$ and $f$ ).

\section{Determination of controlling condition}

Instigators as well as possible inhibitors of the tics were sought in the assessment of the stimulus conditions associated with the problem behavior. Information about stimulus conditions was obtained from Tagalong observation of the patient's behavior in hospital situations to which he had daily, voluntary exposure. Examples of these are given in Table 1 where it may be seen that the lowest rate was 2 for the vocal tic, obtained when the patient was reading aloud in his own hospital room, and that the highest rate of 6.8 occurred when he was laughing, joking and talking with other patients during and after a meal. Exposure Tours consisted of more systematic, planned exposure to stimulus conditions and yielded moderate to large differences in rates for the vocal and neck tic (see Fig. 2). 
Probes were undertaken to observe whether conditions thought to be important in controlling the tics actually caused variation in the rate. The results are given in Fig. 3 . When the patient was working alone in the observation room, the rates were among the lowest obtained in the entire assessment. Likewise, it may be seen that talking to a stranger greatly increased the rate as compared with talking to a familiar person, the therapist. The lowest rate of all (less
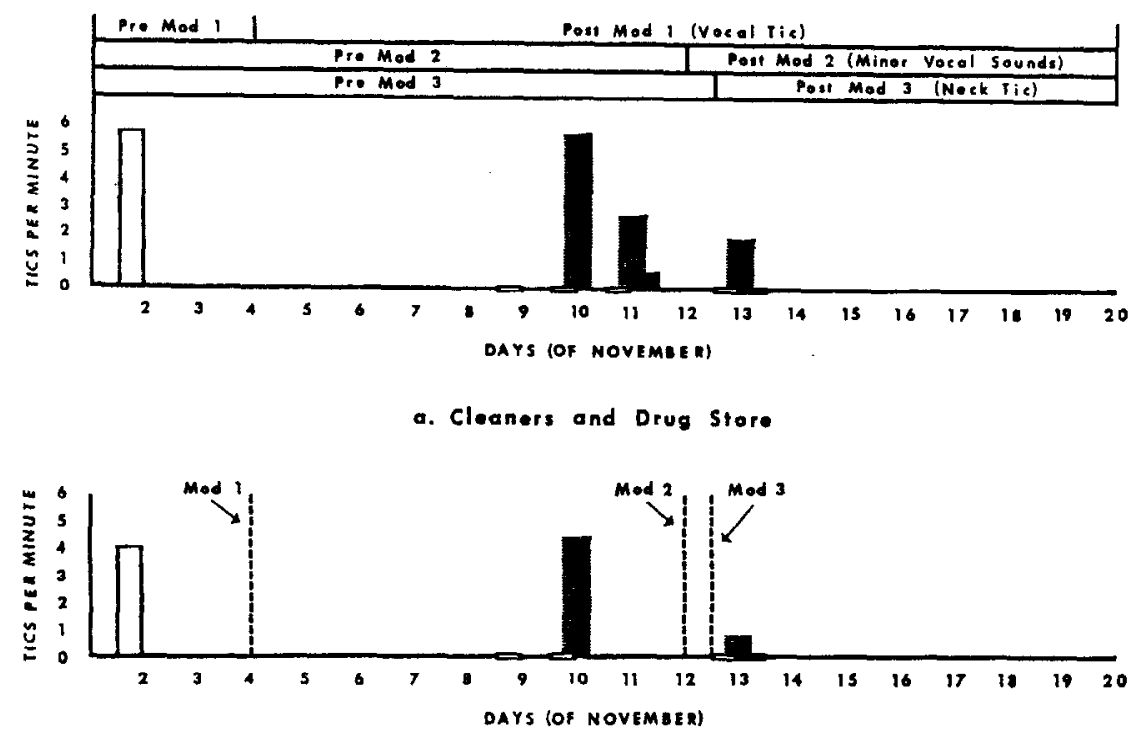

b. Church

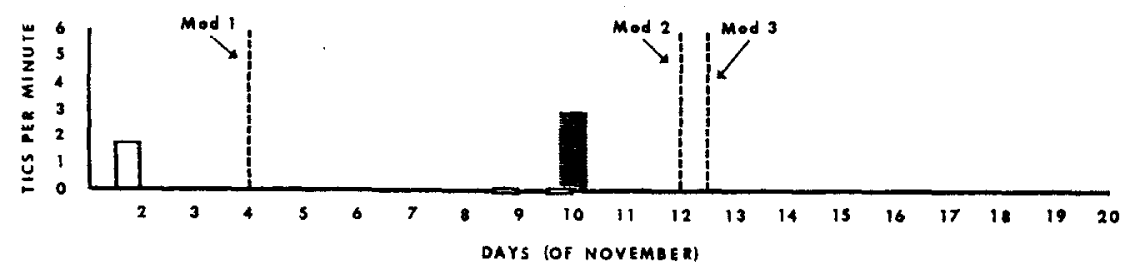

c. Palient's Hospital Room

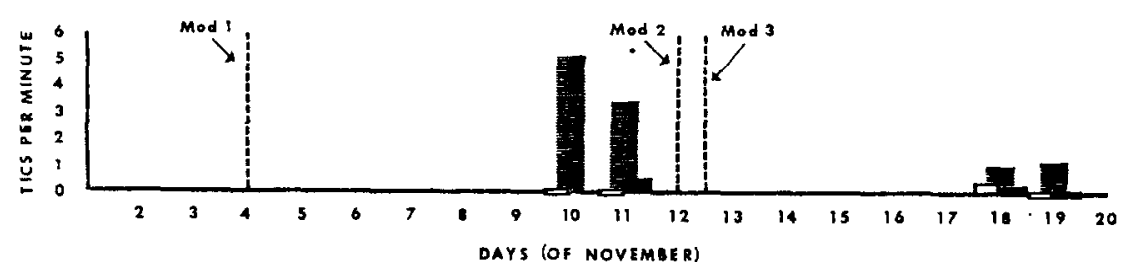

d. High School 

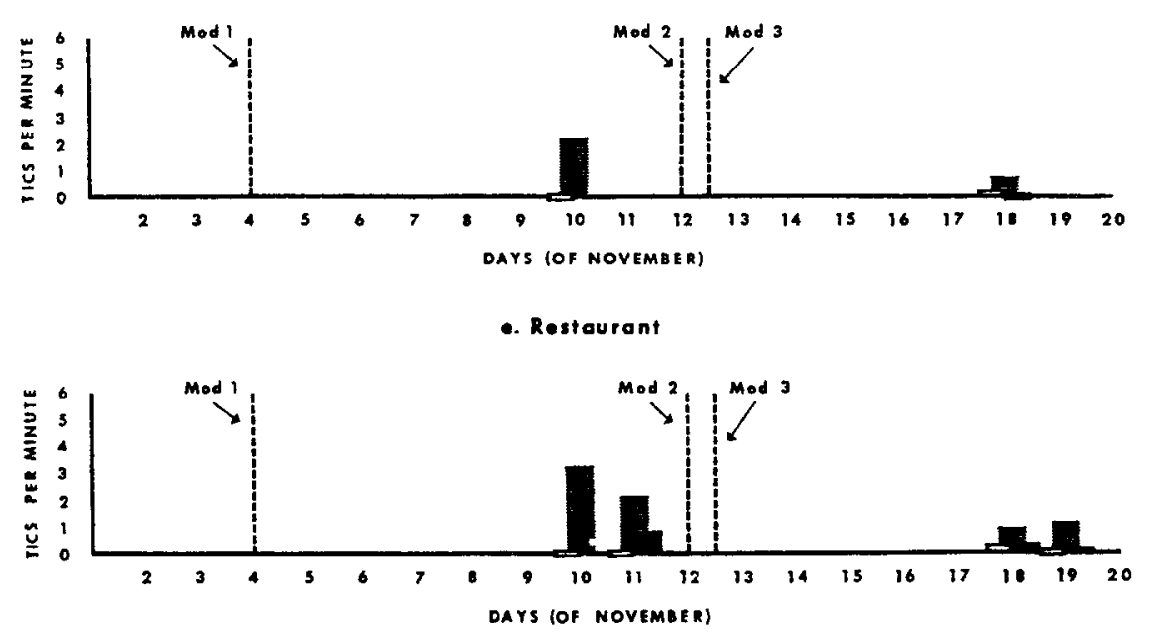

f. Library

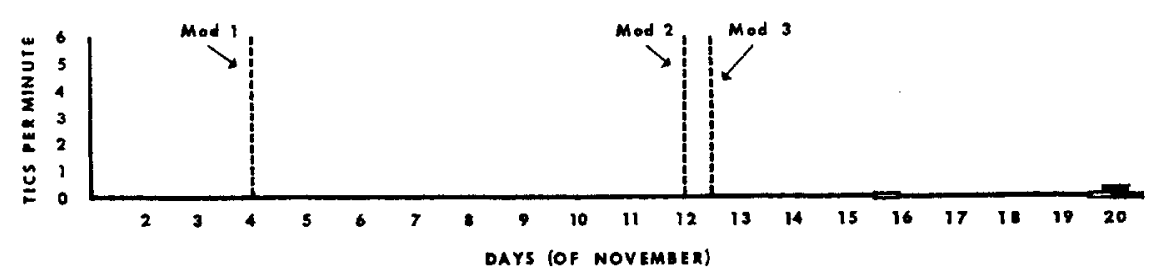

g. Super Markel

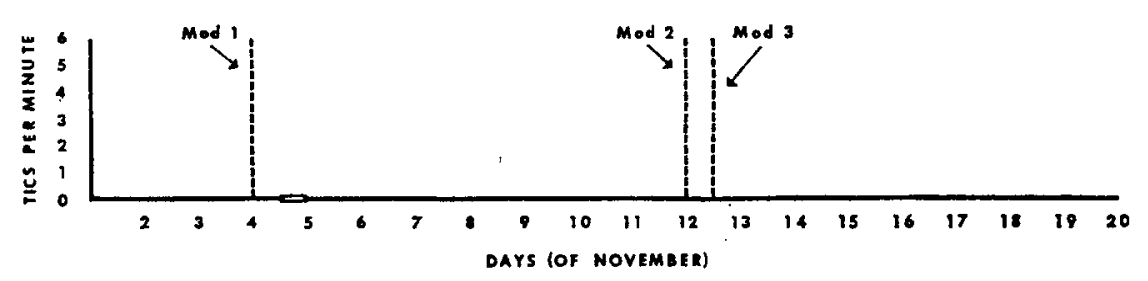

h. Obeervation Room
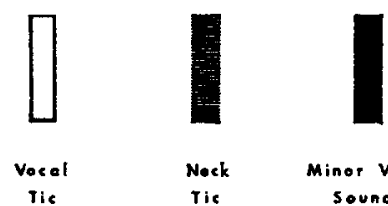

Nock

Minor Vocal

(Bark)

Sounds

("Tuss")

FIG. 2. Tics per min for places patient was taken on Exposure Tours for vocal tic, minor vocal sounds, and neck tic. Rates based upon 10-min observation periods up to and including 11 November, except for 11-5 which was $45 \mathrm{~min}$. From 11 November, the periods were $15 \mathrm{~min}$ each. 


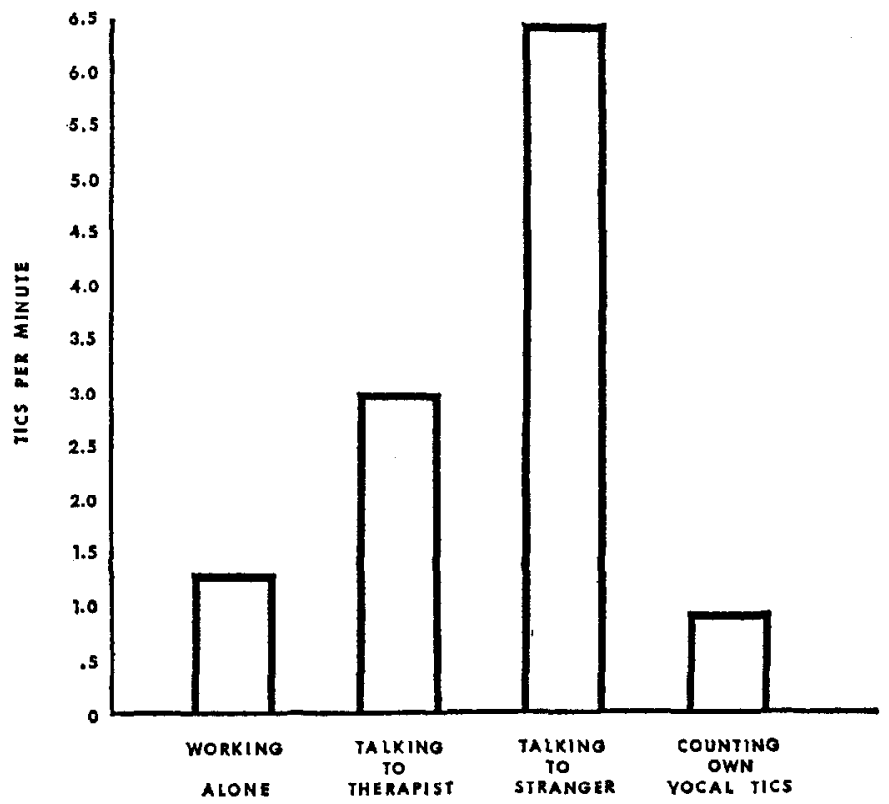

FIG. 3. Vocal tics per min for probes conducted in observation room. Length of observation periods were 60 min for working alone and 9,10 and $20 \mathrm{~min}$ for the others, respectively.

than 1 per $\min$ ) was obtained when the patient was asked to count his own tics for a period of $20 \mathrm{~min}$, using a simple wrist counter.

\section{Environmental and behavioral resources}

The patient came from a small, remote community in the northern part of the state and because of the distance and lack of time, it was not possible to complete an assessment there nor to introduce modification in the patient's natural environment, as would have been ideal. Furthermore, there was a limited amount of time authorized for work on the tic and this precluded the use of behavioral modification techniques that involve long periods of time. The entire period actually embraced 25 days.

\section{Behavioral objectives}

On the basis of information collected up to this point, the objectives were, first, to reduce the rate for the vocal tic, which was clearly most socially stigmatic, and, if time permitted, to begin work on the neck tic.

\section{MODIFICATION}

Plan

The assessment had indicated that selfmonitoring produced the lowest rate for the vocal tic and that it was the most certain technique to serve as a possible inhibitor of tics. Thus, the plan called for instituting self-monitoring as the first part of modification.

The assessment also provided information concerning the relative degrees to which other stimulus conditions served to elicit differential rates of the tics. One way to endeavor to reduce the instigating capability of such stimulus conditions is to produce responses incompatible with tics. To the extent that profound muscular relaxation is incompatible with the convulsive and spasmodic muscular contractions of the tics, the principle of reciprocal inhibition would be applicable (Wolpe, 1958). (It is this presumed physiological incompatibility of muscular relaxation and tics that justifies the use of reciprocal inhibition procedures in this case, not the assumption that the tics were based on anxiety, for the assessment did not disclose that 
anxiety alone was related to the rate of tic behavior.) To our knowledge, little work has been done on the use of relaxation with tics. Although Stevens and Blachly (1966) employed relaxation without success in a case with the Tourette syndrome, Clark (1963) reported modest success in the use of relaxation with a muscular spasm of an hysterical nature and McPherson (1967) found that relaxation helped in reducing the involuntary movements of Huntington's chorea.

Concerning the haloperidol the patient was taking, it was known that the dosage could not be increased without adverse side effects, such as excessive drowsiness. However, if the modification plan were successful, it was hoped to take the patient off the drug, assuming this to be feasible medically.

\section{Implementation}

Self-monitoring for the vocal tic was undertaken in mid-morning of the third day after the beginning of baseline observation (November 4). It was explained to the patient that we had observed the usefulness of self-monitoring from an earlier probe, undertaken during assessment, and that we believed this would be valuable for him to do in helping him to reduce his tics. He was provided with a quiet lever counter and asked to count all noises relating to the vocal tic, to do this all day and to continue the monitoring until instructed otherwise. He was to check the counter every $15 \mathrm{~min}$, report the count to the observer who followed him around the first day, to reset the counter and resume recording. Brief practice was given in how to use the counter unobtrusively and to count a tic when it occurred. During the first day, the observer followed the patient, collected the information concerning the number of tics from the patient, and, observed the tics, as before, on a time-sampling basis. The next day the same procedure was followed except that the patient was instructed to record the counts of his tics when the observer was not present. Whenever his rate was 0.5 or less, he was commended by the observer for the reduced rate.
On the third day the patient was instructed to record any muffled sounds separately from those that were like the original vocal tic and, on the following day, the recording periods were lengthened from $15 \mathrm{~min}$ to $1 \mathrm{hr}$.

Self-monitoring of the minor vocal sounds and neck tic also consisted of an explanation, instructions, a practice session, frequent recording periods, surveillance by the observer, and verbal approval for low rates.

Following the procedure outlined by Wolpe (1969), relaxation training was undertaken for a period of 6 days (from 5 to 11 November). After this, scenes capable of making the patient tense were presented imaginally following a procedure directly comparable to that employed in systematic desensitization. The hierarchy of scenes capable of producing muscular tension was drawn up from observation of the patient in different situations as well as from the patient's self report. In order from the least to the most tension producing, the hierarchy was as follows: his room in the hospital, the drug store, the cleaners, the church, the library, the restaurant, the University High School, and the new city High School. In addition, there was periodic in vivo scene exposure during this period. During the last 3 days of the patient's tenure in the hospital (from 17 to 20 November), there was imaginal exposure to scenes from the home hierarchy which was based entirely on the patient's self report. The home hierarchy progressed from driving a car, being in the woods, patient's own house, brothers' houses, the local garage, a local food store, his church, any dance, his friend's house when family was there, the coffee shop, to the local school, the most tension producing.

Because of the evident success of the modification, the patient was taken off the drug beginning 11 November but placed back on it on 19 November after the rate of vocal and neck tics increased slightly and the patient complained of increased muscular tension.

All of the data produced by the patient for his recording of the frequency of vocal tics, minor vocal sounds and neck tics were examined. 
Unfortunately, the rates were all essentially less than one, even for the neck tics prior to modification, and there was a low relationship between the patient's counts and the observer's because of the patient's under recording. Several sessions were undertaken expressly to improve the accuracy of the patient's recording by calling to his attention occasional tics that were observed. If there was any effect of the training sessions, it was minor and temporary.

\section{Results}

The self-monitoring reduced the vocal tic rapidly and markedly judging from the data presented in Fig. 1. Specifically, the rate was 4.5 in the morning of the day just before the introduction of self-monitoring and, following the introduction of self-monitoring later that day, the rate went essentially to zero. The rate actually attained zero 2 days later and remained there until 12 days later (18 November) at which time two of the original vocal tics were noted. Since arranging to have him stop taking the drug (on 11 November) we had observed an increasing excitability, tenseness and difficulty in achieving relaxation. Finally, the occurrence of two vocal tics caused us to arrange to have him placed back on the drug the following day (19 November), after which there were no more vocal tics.

The results presented in Fig. 2 generally indicate equally clear reductions in the vocal tic. We refer particularly to the difference in rates before and after modification for the situations of the cleaners and drug store, the church and the patient's hospital room (Figs. 2a, b, and c). The remaining rates are post modification and are zero except for a very small increase on the last day that the patient was off the drug (18 November) for Exposure Tours of the high school (Fig. 2d), restaurant (Fig. 2e), and the library (Fig. 2f). All rates were zero again on the days after the patient resumed taking the drug (19 and 20 November).

Despite the reduction in the vocal tic proper, there were subtle aspects of response noted by us after the vocal tic essentially disappeared following modification. At first there appeared to be a muffled bark imbedded in laughing or talking, then there was sound that consisted of the passage of the air through the nose in a soft plosive manner. Both responses were observed just after modification started and evidently disappeared a few days after modification. The most noteworthy response, however, was what we have called the minor vocal sounds and these consisted of a "tsss" sound made by passing the air between the tongue and roof of the mouth. Although periodically repetitive, these sounds clearly lacked the convulsive, involuntary quality of the vocal tic.

Base rates were taken for these minor vocal sounds on 11 November and on the morning of the next day. Self-monitoring was undertaken on the afternoon of the second day, and, as Fig. 1 indicates, there was an immediate reduction to zero, then resumption on the next day followed by a reduction to about zero for the remainder of the patient's stay in the hospital. Figure 2 indicates that all changes for the Exposure Tour data show a consistent decrease in the post-modification rates as compared with the pre-modification rates. Note the contrasts for the cleaners and drug store (Fig. 2a), the high school (Fig. 2d), and the library (Fig. 2f). Also, the rates are essentially zero for all data points obtained only after modification, namely, the rates for the church (Fig. 2b), the restaurant (Fig. 2e), the supermarket (Fig. 2g).

Concerning the neck tic, Fig. 1 indicates that following the introduction of self-monitoring there was a gradual and continuing reduction in the rate until it reached that of about one tic in $4 \mathrm{~min}$ on the last day prior to discharge from hospital. Results for the Exposure Tours indicate that all of the post-modification rates for the neck tic are less than those obtained prior to modification. These contrasts involve the cleaners and drug store, the church, the high school, the restaurant, and the library (Figs. 2a, $b, d$, e and $f$ ). Rates for the neck tic on the Exposure Tours never reached zero even just prior to discharge from hospital. The original intense, spasmodic character of the neck tic was 
replaced by a much less violent movement which was at times so slight as to be difficult to discern.

\section{DISCUSSION}

The effect of the self-monitoring was most evident for the vocal tic because the change was dramatic and occurred prior to the introduction of the relaxation and reciprocal inhibition regimen. Self-monitoring also probably served to reduce the minor vocal sounds and the neck tic. However, the changes in both instances were less dramatic than for the vocal tic and may be attributable in part or fully to the relaxation training or the reciprocal inhibition procedure, both of which had been introduced for the vocal tic before the self-monitoring was substituted for the other two tics. Because the results for the neck tic indicated a reduction in rate prior to the introduction of self-monitoring, it seems plausible to argue that the relaxation and the reciprocal inhibition procedure may have been effective to some extent. It seems probable, also, that the haloperidol served to reduce somewhat the rate of tic behavior. As indicated, this drug has been the one found to be most successful to date with this particular syndrome. The drug inhibits motor activities in animals in open field tests and inhibits conditioned avoidance responses in a manner similar to that of the phenothiazines.

The study provides information that may contribute to a greater understanding of selfmonitoring. The direction of change here was clearly "positive," i.e., the self-monitoring evidently reduced the problem behavior. Studies have shown both positive and negative selfmonitoring effects. For example, Rutner and Bugle (1969) reported that frequencies of selfrecorded auditory hallucinations were greatly reduced when the patient kept counts under private conditions. Stollak (1967) found weight reductions associated with diary recording of the kinds and amounts of food eaten combined with frequent contacts with a graduate student who reviewed the diary data and praised moderate food intake. However, McFall (1970), in a classroom-based experiment, found an increase rather than a decrease in smoking for subjects asked to record the number of cigarettes smoked.

The rate of change in self-monitoring also may vary. In the case of the vocal tic, the decrease was almost instantaneous and precipitous whereas the changes for the minor vocal sound and neck tic, if due to self-monitoring, were more gradual. More gradual changes were observed in the studies cited above. Furthermore, the rate of change was found in this study to be approximately the same in different situations. That is, the amount by which the rate for the vocal tic, minor vocal sound, and neck tic were reduced in one stimulus context was similar to the amount of reduction in other situations (see Fig. 2). Such apparent pan-situational change clearly does not characterize all behavior changes.

In addition to the nature of the self-monitoring effect, considerable uncertainty attends the question of what its functional behavioral properties may be. In the case of rapid reduction of problem behavior following self-monitoring, as was the case for the vocal tic, the effects are largely a function of discrimination or eliciting antecedents for the problem behavior. In contrast, a gradual reduction allows response feedback to occur more readily and, hence, the effects of such factors as self-administered aversiveness or the withholding of self-reinforcement may then be operative. In either case, stimuli produced by the observation of one's own behavior may be crucial in mediating a self-monitoring effect. In the case of the vocal tic, the patient's own observations of the tics tended to underrepresent the rate; in other words, many tics occurred that were not attended to or tracked by him. Indeed, in the case of the minor vocal sound that emerged after the reduction of the vocal tic, the patient was totally unaware of the new sound until we called it to his attention as part of its self.monitoring. The vocal and neck tics were clearly known to the patient before selfmonitoring and were a source of embarrassment. However, not every occurrence of these 
behaviors was attended to by the patient. Careful behavioral investigation of awareness phenomena and observation of one's own behavior as they affect changes in one's own behavior should contribute greatly to the understanding of self-monitoring.

There are several noteworthy features of the procedure employed in this study to guide the therapeutic activities. One is the essentially empirical nature of the assessment. The assessment of the tics by Tagalong observation, Exposure Tours in real-life situations and by tests based upon probes all served to highlight the remarkable extent to which the tics were differentially elicited by various stimulus conditions. Such information may allow the therapist to construct empirically based hierarchies of inhibiting and instigating stimulus conditions. The modification undertaken in this study was very much guided by the data yielded in the assessment, especially the information about self-monitoring as an inhibitor of tics. However, the data were collected in the hospital and in the city where the hospital was located. This meant that the data were not necessarily adequate to plan a maintenance procedure for the home situation, to which the patient returned.* As previously stated, it was not feasible to conduct the assessment and modifcation in the patient's home locale, but had they been undertaken, then this step-wise procedure would have been applicable. Different procedural guidelines need to be developed for the special circumstances in which assessment and modification cannot be undertaken in the patient's home environment.

The assessment and monitoring techniques yielded data relating to the phenomena of "symptom substitution," namely, to what happens to repertoire elements when one "problem" component is changed. The minor vocal sound did emerge after the vocal tic was reduced to zero. It was topographically very different from the bark of the vocal tic and, indeed, could not really be called a tic. Minor as it was, however, it was clearly a behavior that emerged following the reduction of the vocal tic. The only phenomenon known to us that is similar to this is the emergence of a hiss in the young patient with Gilles de la Tourette studied by Stevens and Blachly (1966). However, the hiss occurred after many unsuccessful attempts to alter the rate of the tics and before using haloperidol successfully. Other than the minor vocal sound, no other such behaviors were observed in our study following the introduction of modification for the sound itself or for the neck tic. Furthermore, the neck tic diminished rather than increased after the modification was undertaken for the vocal tic and after the vocal tic diminished. Altogether, the results are not consistent with a literal doctrine of symptom substitution as applied here, i.e. another problem behavior did not appear following the modification of each of the target behaviors addressed in the modification. However, the results raise the possibility that the vocal tic may have been a member of the same operant class as the minor vocal sound. It is uncertain as to whether the neck tic could also have been a member of this class.

\section{REFERENCES}

Abuzzahas F. S. (1970) Some uses of haloperidol in the treatment of psychiatric conditions, Psychosomatics 11, 188-193.

AsCHER E. (1948) Psychodynamic considerations in Gilles de la Tourette's disease with a report of five cases and discussion of the literature, Amer. $J$. Psychiat. 105, 267.

BalthazaR K. (1957) UUber das Anatomische Substrat der Generalisierten Tic-Krankheit. Entwicklungshemmung des corpus Striatum, Archive Psychiat. Nervenkr. 195, 531-549.

Challas G. and Brauer W. (1963) Tourette's disease; relief of symptoms with R1625, Am. J. Psychiat. $120,283$.

Clark D. F. (1963) The treatment of hysterical spasm and agoraphobia by behavior therapy, Behav. Res. \& Therapy 1, 245-250.

Connell P. H., Corbett J. A., Horne D. J. and Mathews A. M. (1967) Drug treatment of adolescent tiqueurs - a double blind trial of diazepam and haloperidol, Brit. J. Psychiat. 113, 375-381.

*Because of the distance to the patient's home, there was no way to assure the implementation of a modification plan after discharge. In recognition of this fact, this study was purposely restricted to what was undertaken and observed in the hospital context. 
Corbett J. A., Mathews A. M., Connell P. H. and Shapiro D. A. (1969) Tics and Gilles de la Tourette's Syndrome: a follow-up study and critical review, Brit. J. Psychiat. 115, 1229-1241.

ERIKsson B. and Persson T. (1969) Gilles de la Tourette's Syndrome: two cases with an organic brain injury, Brit. J. Psychiat. 115, 351-353.

Feild J. R., Corbin K. B., Goldstein N. P. and KLAss D. W. (1966) Gilles de la Tourette's Syndrome. Neurolog 16, 453-462.

FORD C. V. and GOTTLIEB F. (1969) An objective evaluation of haloperidol in Gilles de la Tourette's Syndrome, Dis. Nerv. System 30, 328-332.

Gambrill E. D., Thomas E. J. and CARTER R. D. (1971) Procedure for sociobehavioral practice in open settings, Social Work 16, 51-62.

GILLES DE LA TOURETTE (1885) Étude sur une affection nerveuse, caractérisée par de l'incoordination motrice, accompagnée d'écholalie et de coprolalie. Archives de Neurologie 9, 159.

LuCAs A. R. (1967) Gilles de la Tourette's disease in children: treatment with haloperidol, Amer. $J$. Psychiat. 124, 243-245.

Lucas A. R., Kauffman P. E. and Morris E. M. Gilles de la Tourette's disease-a clinical study of fifteen cases. J. Amer. Acad. Child Psychiat. 6, 700-722.

MAHLER M. S. (1944) Tics and impulsions in children: a study of motility, Psychoanal Quart. 13, 430.

Mahler M. S., Luke J. A. and DalttofF W. (1945) Clinical follow-up study of the tic syndrome in children, Am. J. Orthopsychiat. 15, 631 .
MCFall R. M. (1970) Effects of self-monitoring on normal smoking behavior, J. Cen. \& Clin. Psych. 35, 135-143.

Morphew J. A. and SiM M. (1969) Gilles de la Tourette's Syndrome-a clinical and psychopathological study, Brit. J. Med. Psychol. 42, 293-301.

Rutner I. T. and Bugle C. (1969) An experimental procedure for the modification of psychotic behavior, J. Cen. \& Clin. Psych. 33, 651-654.

STEVENS J. K. and BLACHLY P. H. (1966) Successful treatment of Maladie des Tics: Gilles de la Tourette's Syndrome, Amer. J. Dis. Child 112, 541-545.

ShapIRo A. K. and ShapIRo E. (1968) Treatment of Gilles de la Tourette's Syndrome with haloperidol, Brit. J. Psychiat. 114, 345-350.

Stollak G. Weight loss obtained under different experimental procedures, Psychotherapy: Theory Res. \& Pract. 4, 61-64.

Thomas E. J., Carter R. D. and Gambrill E. D., eds. (1970) Utilization and appraisal of socio-behavioral techniques in social welfare-pilot phase. Final report on research supported by the Department of Health, Education and Welfare, Social Rehabilitation Service, Grant SRS-CRD 425-C1-9, Ann Arbor, Michigan, University of Michigan School of Social Work.

WOLPE J. (1958) Psychotherapy by Reciprocal Inhibition. Stanford Univ. Press, Stanford, Calif.

Wolpe J. (1969) The Practice of Behavior Therapy. Pergamon Press, New York.

YATES A. J. (1970) Behavior Therapy. Wiley, New York.

Acknowledgements-We wish to thank Marjorie Becker, Ph.D., Coordinator of the Parkview Rehabilitation Unit, and Robert Koski and Robert Stinson, DVR Coordinators who provided encouragement and support for this study. 